\title{
Direct Post-traumatic Carotid Cavernous Fistula Treated by Endovascular Intervention
}

Guilherme Brasileiro de Aguiar*, Mario Luiz Marques Conti and Jose Carlos Esteves Veiga

Department of Surgery, Division of Neurosurgery, Faculdade de Ciências Medicas da Santa Casa de Misericórdia de São Paulo, São Paulo, Brazil

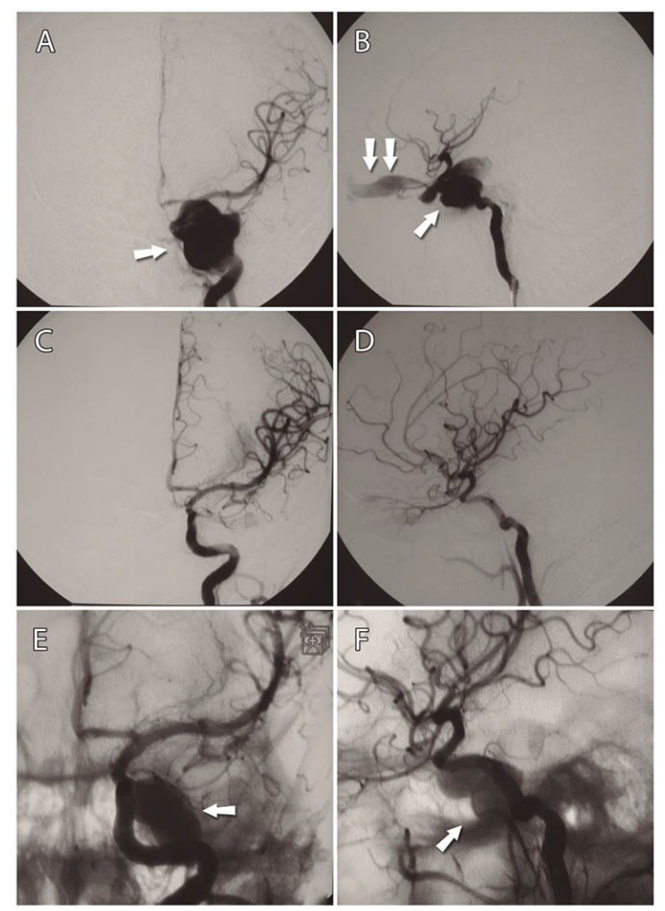

Figure 1: Carotid cavernous fistula treated by endovascular intervention.

\section{Clinical Image}

The Carotid-Cavernous Direct Fistula (CCF) is a high-flow injury resulting from the wall laceration of the cavernous segment of the internal carotid artery and its subsequent communication with the cavernous sinus [1]. The vast majority of direct CCF is traumatic but direct posttraumatic CCF represents a rare entity, occurring in only 0.17 to $1.01 \%$ of all Traumatic Brain Injury (TBI) [1,2]. Clinical presentation may involve impairment of cranial nerves III, IV, V and VI, causing paralysis on the extrinsic eye movement and diplopia, besides the emergence of headache, retro-orbital pain, chemosis and proptosis and even intracranial hemorrhage [2].

The best treatment option envolves the endovascular occlusion of the fistula, usually with detachable balloons [1,2]. The figure shows images of an endovascular treatment of a direct post-traumatic CCF in a woman, 39 years old, who suffered a car accident with TBI. In Figures 1A and 1B it is possible to demonstrate the early opacification of the left cavernous sinus (arrow), featuring the direct CCF involving the left internal carotid artery. Also, in B, the double arrow shows the early and retrograde opacification of the superior ophthalmic vein. The endovascular treatment with occlusion of the fistula with two detachable balloon was performed, and in the following images (Figures 1C and 1D), it's possible to demonstrante that there is no early opacification of the cavernous sinus, and there is normal opacification of the left brain parenchyma. In Figures $1 \mathrm{E}$ and $1 \mathrm{~F}$ it's possible the visualization of the detachable balloons.

\section{References}

1. Grumann AJ, Boivin-Faure L, Chapot R, Adenis JP, Robert PY (2012) Ophthalmologic outcome of direct and indirect carotid cavernous fistulas. Int Ophthalmol. 32: 153-159.

2. Kanamalla US, Jungreis CA, Kochan JP (2008) Direct Carotid Cavernous Fistula. Interventional neuroradiology. (1stedn), New York: Informa Healthcare USA

*Corresponding author: Guilherme Brasileiro de Aguiar, Department of Surgery, Division of Neurosurgery, Faculdade de Ciências Medicas da Santa Casa de Misericórdia de São Paulo, São Paulo, Brazil, Tel: 5511 21767000; E-mail: guilhermebraguiar@yahoo.com.br

Received February 18, 2015; Accepted February 21, 2015; Published February 23, 2015

Citation: de Aguiar GB, Conti MLM, Veiga JCE (2015) Direct Post-traumatic Carotid Cavernous Fistula Treated by Endovascular Intervention. J Trauma Treat 4: i103. doi: 10.4172/2167-1222.1000i103

Copyright: @ 2015 Aguiar GBD, et al. This is an open-access article distributed under the terms of the Creative Commons Attribution License, which permits unrestricted use, distribution, and reproduction in any medium, provided the original author and source are credited. 